\title{
Effects of Early Neurological Deterioration in Acute Ischemic Stroke on Multiple Dimensions of Functional Outcomes Using Propensity Score Matching Analysis
}

\section{Jian-Feng Qu ( $\nabla$ geoffrey-197830@163.com )}

Dongguan People's hospital

\section{Huo-Hua Zhong}

Department of Neurology, Dongguan People's Hospital (Affiliated Dongguan Hospital, South Medical University), Dongguan, Guangdong Province, China

\section{Wen-Cong Liang}

Department of Neurology, Dongguan People's Hospital (Affiliated Dongguan Hospital, South Medical University), Dongguan, Guangdong Province, China. Faculty of Neurology, Guangdong Medical University, Zhanjiang, Guangdong Province, China

\section{Yang-Kun Chen}

Department of Neurology, Dongguan People's Hospital (Affiliated Dongguan Hospital, South Medical University), Dongguan, Guangdong Province, China

\section{Yong-lin Liu}

Department of Neurology, Dongguan People's Hospital (Affiliated Dongguan Hospital, South Medical University), Dongguan, Guangdong Province, China

\section{Shi-fang Wang}

Department of Neurology, Dongguan People's Hospital (Affiliated Dongguan Hospital, South Medical University), Dongguan, Guangdong Province, China

\section{Research}

Keywords: Acute ischemic stroke, early neurological deterioration, functional outcomes, participation restriction

Posted Date: November 24th, 2020

DOI: https://doi.org/10.21203/rs.3.rs-110582/v1

License: (c) (i) This work is licensed under a Creative Commons Attribution 4.0 International License. Read Full License 


\section{Abstract}

Background: Early neurological deterioration (END) is common in acute ischemic stroke (AIS), but its effect on functional outcomes is not well understood. The aim of the present study was to explore the effects of END on multiple dimensions of functional outcomes.

Methods: In the present study, 256 patients with AIS were analyzed. All patients were followed up for 1 year. We used the modified Rankin Scale (mRS) to assess body function impairment, the Lawton activities of daily living scale to assess activity limitations, and the reintegration to normal living index (RNLI) to assess participation restrictions. Brain magnetic resonance imaging was performed to identify acute infarcts and preexisting abnormalities, such as white matter lesions, medial temporal lobe atrophy, microbleeds, and silent lacunae. To reduce the effects of a lack of randomization, we conducted a propensity score analysis.

Results: The study sample consisted of 185 men (72.3\%) and 71 women (27.7\%). Sixty-one patients (23.8\%) had END. Before matching, patients with END had higher levels of small artery-type stroke, higher National Institutes of Health Stroke Scale scores on arrival, higher systolic blood pressure on admission, and larger infarct volumes. After matching, there were no significant differences between the two groups in any clinical or neuroimaging variables, except for stroke subtype and cortical region infarct. Logistic regression analysis revealed that END was a significant predictor of poor mRS (odds ratio [OR], 3.829; 95\% confidence interval [CI], 1.367-10.723, $p=0.011$ ) and poor RNLI (OR, 2.777; 95\% Cl, 1.133-6.806, $p=0.026)$ scores after adjusting for confounding factors.

Conclusions: END is relatively common in AIS, with an incidence of $23.8 \%$. END might be able to predict poor functional outcomes, including body function impairment and reduced social participation.

\section{Background}

Stroke is a leading contributor to mortality and long-term morbidity in China, and the lifetime stroke risk in the Chinese population is estimated to be $39.3 \%[1,2]$. Early neurological deterioration (END) is common in a fraction of patients with acute ischemic stroke (AIS) [3, 4]. The reported frequency of END in AIS varies widely, ranging from 5$40 \%$ [5-8]. Previous studies have revealed some of the main clinical and radiological factors predicting END, including high blood glucose levels, older age, more severe stroke, history of diabetes, coronary heart disease, nonuse of aspirin, high levels of high-sensitivity C-reactive protein, no recanalization, re-occlusion, brain swelling, and the presence of an infarction $>1 / 3$ of the middle cerebral artery territory [9-12].

It has been reported that END may increase the probability of poor outcomes. For example, Liu et al. found that END was a predictor of poor modified Rankin scale (mRS) scores after 1 year [13]. Furthermore, Mori et al. reported that END after intravenous recombinant tissue plasminogen activator therapy was independently associated with death and dependency (mRS 3-6) [14]. However, evaluating the relationship between only these outcomes and END remains limited. The World Health Organization International Classification of Functioning, Disability, and Health (WHO-ICF) categorizes disease consequences into three different dimensions: body function impairments, activity limitations, and participation restrictions [15]. Despite these guidelines, which capture the complex nature of functioning, our understanding of functional outcomes after stroke combined with END is mainly limited to activities of daily living (ADL), which is often narrowly defined and evaluated using only the mRS [16]. However, functional status also involves the basic ADL and the instrumental ADL, which are both vital parameters to consider after stroke. In addition, stroke survivors often experience participation restrictions in the chronic phase [17]. However, few 
studies have identified the impact of END on these multiple functional domains. In the present study, we aimed to explore the effects of END on these multiple functional outcomes.

\section{Methods}

\section{Participants and setting}

The study was conducted at the Department of Neurology, Dongguan People's Hospital, between January 1, 2018, and December 30, 2018. The inclusion criteria for the study were: (1) aged over 18 years; (2) first AIS occurred within 7 days before admission and was diagnosed according to the American Heart Association Stroke Council criteria [18]; (3) had complete brain magnetic resonance imaging (MRI) examinations; and (4) had an mRS score < 3 before admission. The exclusion criteria were: (1) transient ischemic attack, cerebral hemorrhage, subdural hematoma, or subarachnoid hemorrhage; (2) incomplete clinical data (e.g., incomplete brain MRI); (3) died before discharge; (4) severe comorbidities (e.g., liver, kidney, heart, or respiratory failure, or malignant tumors); (5) unable to finish the assessment at follow-up because of severe hearing disabilities, visual disabilities, language disorders, or cognitive impairment; and (6) refused to sign a consent form.

The study protocol was approved by the Ethics Committee of Dongguan People's Hospital. The consent of all subjects was obtained in accordance with the Declaration of Helsinki.

\section{Data collection}

Information about demographic variables (e.g., age, sex) and vascular risk factors (e.g., hypertension, diabetes mellitus, atrial fibrillation) was collected. We also recorded clinical data, including stroke severity, blood pressure, stroke subtype, lesion location, in-hospital treatment (antiplatelet, anticoagulation, and statins), and laboratory data. The severity of stroke was assessed using the National Institutes of Health Stroke Scale (NIHSS) [19]. The subtype of ischemic stroke was evaluated using the Trial of Org 10172 in Acute Stroke Treatment (TOAST) subtype system [20]. Laboratory data included fasting blood glucose, glucosylated hemoglobin A1c, total cholesterol, triglycerides, high-density lipoprotein, low-density lipoprotein, homocysteine, white blood cells, hemoglobin, fibrinogen, prothrombin time, and creatinine. Blood pressure was measured and recorded shortly after admission, and the laboratory data were tested within 24 hours after admission.

\section{Definition of END}

We evaluated NIHSS scores on the day of admission, and then daily over the

following 7 days after admission. We defined END as an increase in NIHSS score $\geq 2$ points within $72 \mathrm{~h}$ after admission [21].

\section{Patient follow-up}

All follow-up assessments were completed by the patients. We assessed multiple outcomes at 12-15 months after the index stroke. Based on the WHO-ICF (2002) [15], we selected one measure to evaluate each level of functioning: body function impairment was assessed using the mRS, activity limitation was assessed using the Lawton ADL scale [22], and participation restriction was evaluated using the Chinese version of the reintegration to normal living index (RNLI) [23].

$A D L$ is composed of basic $A D L$ and instrumental $A D L$. The components of basic ADL include six different levels of abilities for toilet activity, feeding, dressing, grooming, physical ambulation, and bathing. The total basic ADL score 
is calculated by summing up the points for each item, with a maximum score of 24 . The Lawton instrumental ADL score is composed of eight different domains: using a telephone, shopping, food preparation, housekeeping, laundry, mode of transportation, responsibility for own medications, and handling finances. The total instrumental ADL score is calculated by summing up the points for each item, with a maximum of 32. Therefore, the total ADL score ranges from 14 to 56. A higher ADL score reflects poorer ADL performance [22].

The RNLI is an 11-item questionnaire that targets nine domains affected by incapacitating events: mobility, self-care ability, daily activities, recreational activities, general coping skills, family roles, social activities, personal relationships, and presentation of self to others. Each item is scored from 1 (minimal reintegration) to 10 (complete reintegration), with a total scale range of 11-110. A lower RNLI score reflects poorer participation in normal living [23].

Poor outcome was defined as follows: body function, $m R S$ score $\geq 3$; activity limitation, ADL score $>$ the $75 \%$ quartile; and participation restriction, RNLI score $<$ the $25 \%$ quartile.

\section{MRI assessments}

Each participant underwent brain MRI, including T1-weighted imaging, T2-weighted imaging, and diffusion-weighted imaging (DWI), within 7 days of admission using a 3.0 T system (Sonata, Siemens Medical, Erlangen, Germany). DWI spin echo-planar imaging (EPI) $(\mathrm{TR} / \mathrm{TE} /$ excitation $=2162 / 76 / 1$, matrix $=128 \times 128$, field of view $[\mathrm{FOV}]=$ $230 \mathrm{~mm}$, slice thickness $/ \mathrm{gap}=6 \mathrm{~mm} / 1 \mathrm{~mm}$, EPI factor $=47$, acquisition time $=25.9 \mathrm{~s})$ with three orthogonally applied gradients was used, with a b value of 0 and 1000. Axial SE T1 (TR/TE/excitation $=488 / 15 / 1, F O V=230 \mathrm{~mm}$, slice thickness $/ \mathrm{gap}=6 \mathrm{~mm} / 1 \mathrm{~mm}$, matrix $=256 \times 256$, time of acquisition $=1 \mathrm{~min} 24.8 \mathrm{~s}$ ) and TSE T2 $(\mathrm{TR} / \mathrm{TE} /$ excitation $=3992 / 110 / 2$, turbo factor $=15, \mathrm{FOV}=230 \mathrm{~mm}$, slice thickness $/ \mathrm{gap}=6 \mathrm{~mm} / 1 \mathrm{~mm}, \mathrm{matrix}=512$ $\times 512$, time of acquisition $=1 \mathrm{~min} 55.8 \mathrm{~s}$ ) images were also acquired.

A neurologist (JFQ) who was blinded to the patients' clinical information measured the MRI variables. The MRI measurements included acute infarcts and preexisting abnormalities, as follows:

(1) Acute infarction. Both the site and volume of acute lesions in the DWI sequence were recorded. The sites of the acute infarcts were classified into cortical regions, subcortical regions, and infratentorial regions. Cortical regions included the frontal, temporal, parietal, and occipital lobes; subcortical regions included the white matter, basal ganglia, and thalamus; and infratentorial regions included the brainstem and cerebellum. Acute infarcts were defined as areas of restricted water diffusion identified on DWI with b values of 1000 , together with hypointensity on the corresponding apparent diffusion coefficient map. The total area of acute infarcts on DWI was measured using manual outlines. The total volume was calculated by multiplying the total area by the sum of the slice thickness and the gap.

1. White matter lesions (WMLs). WML severity was graded using the four-point scale described by Fazekas et al [24]. WMLs included periventricular hyperintensities and deep white matter hyperintensities, which were scored separately on fluid-attenuated inversion recovery images.

2. Medial temporal lobe atrophy (MTLA). MTLA was evaluated using the Scheltens scale [25]. The MRI rater judged the severity of MTLA based on standard images of the coronary section of the MRI (range 0-4), with 0 representing no atrophy and 4 representing severe atrophy.

3. Microbleeds. These were defined as small (2-10 mm) hypointense lesions with a clear margin in susceptibilityweighted imaging [26]. Symmetric basal ganglia calcification and flow void artifacts of the pial blood vessels were excluded. 
4. Silent lacunae. These were visible as focal lesions (diameter $>3 \mathrm{~mm}$ ), with approximately the same intensity as cerebrospinal fluid on MRI [27].

Intra-rater reliability (kappa) tests were carried out on 20 stroke patients with the same MRI rater. The intra-rater agreements for the MRI measurements were good to excellent: volume of infarction-ICC: 0.82; WMLs: 0.86; MTLA: 0.86; microbleeds: 0.80 ; silent lacunae: 0.83 .

\section{Statistical analysis}

Statistical analyses were performed using SPSS for Windows (v24.0, SPSS Inc., Chicago, IL, USA). Descriptive data are presented as proportions, means, or medians, as appropriate. To reduce the lack of randomization, we conducted a propensity score analysis using the SPSS custom dialog. Before matching, we performed a univariate analysis to compare variables between patients with and without END. The propensity score was then developed using a logistic regression model in which the variables with $p<0.05$ in the univariate analysis were entered. After estimating the propensity score, we matched participants using a simple 1:1 matching. After matching was completed, the two matched groups with and without END were compared. Logistic regression models were performed to analyze the relationship between multiple outcomes and END, based on the matched data. In the multivariate logistic regression analyses, the poor outcomes served as dependent variables, while END and other confounding factors served as independent variables. The odds ratio (OR) of END was interpreted as the risk of poor outcomes. The significance level was set at $p<0.05$ (two-sided).

\section{Results}

In this study, 465 patients with first-ever AIS were consecutively admitted. Of these, 55 patients were excluded because they had no MRI data, and 42 were excluded because their MRI data were incomplete. Nine patients were excluded because they died before discharge, 29 patients were excluded because of severe complications, and 13 patients refused to sign their informed consent. During the follow-up, 4 patients died, 54 patients were lost to followup, and 3 patients were unable to finish the RNLI assessment. Hence, 256 patients were finally included in the analysis (Fig. 1).

Compared with the excluded patients, the included patients did not differ significantly in terms of sex (men, $71 \% \mathrm{vs}$. $67.6 \%, p=0.455)$, but differed significantly in age ( $59.9 \pm 11.25$ vs. $63.63 \pm 12.76, p=0.002)$ and NIHSS score on admission (2 [1-3] vs. 3 [2-5], $p<0.001)$.

The study sample consisted of 185 men (72.3\%) and 71 women (27.7\%). Sixty-one patients underwent END, with an incidence of $23.8 \%$. The baseline characteristics of patients with and without END, before and after propensity score matching, are summarized in Table 1. Before matching, patients with END had higher levels of small artery-type stroke, higher NIHSS scores on arrival, higher systolic blood pressure on admission, and larger infarct volumes. After matching, there were no significant differences between the two groups in any clinical or neuroimaging variables, except for stroke subtype and cortical region infarct. 
Table 1

Comparison of clinical and neuroimaging characteristics of END and non-END patients

\section{Prematched}

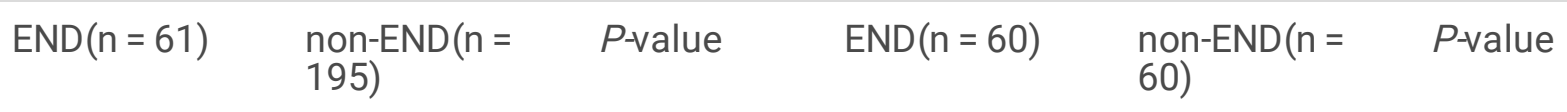

Clinical

\begin{tabular}{|c|c|c|c|c|c|c|}
\hline Age $(\text { years })^{a}$ & $59.21(11.38)$ & $59.71(10.67)$ & 0.756 & $59.28(11.46)$ & $61.37(10.6)$ & 0.303 \\
\hline Male $^{b}$ & $45(73.8 \%)$ & $140(71.8 \%)$ & 0.764 & $45(75 \%)$ & $48(80 \%)$ & 0.512 \\
\hline Hypertension ${ }^{b}$ & $52(85.2 \%)$ & $149(76.4 \%)$ & 0.143 & $51(85 \%)$ & 47(78.3\%) & 0.345 \\
\hline $\begin{array}{l}\text { Diabetes } \\
\text { mellitus }^{b}\end{array}$ & $22(36.1 \%)$ & 68(34.9\%) & 0.865 & $22(36.7 \%)$ & $25(41.7 \%)$ & 0.575 \\
\hline $\begin{array}{l}\text { Atrial } \\
\text { fibrillation }^{d}\end{array}$ & $1(1.6 \%)$ & $10(5.1 \%)$ & 0.241 & $1(1.7 \%)$ & $4(6.7 \%)$ & 0.364 \\
\hline Stroke subtype & & & 0.08 & & & 0.02 \\
\hline Large artery & $30(49.2 \%)$ & $57(29.3 \%)$ & & $29(48.3 \%)$ & 44(73.3\%) & \\
\hline Small artery & $20(32.8 \%)$ & $97(49.7 \%)$ & & $20(33.3 \%)$ & $16(26.7 \%)$ & \\
\hline Cardioembolism & $4(6.6 \%)$ & $5(2.6 \%)$ & & $4(6.7 \%)$ & 0 & \\
\hline $\begin{array}{l}\text { Unknown } \\
\text { etiologies }\end{array}$ & $7(11.5 \%)$ & $36(18.5 \%)$ & & $7(11.7 \%)$ & 0 & \\
\hline $\begin{array}{l}\text { Onset to arrival } \\
\text { time(hour) }{ }^{a}\end{array}$ & $10.85(5.74)$ & $10.63(6.04)$ & 0.796 & $10.85(5.79)$ & $10.99(5.62)$ & 0.892 \\
\hline $\begin{array}{l}\text { NIHSS on } \\
\text { arrivalc }^{c}\end{array}$ & $3(2-4)$ & $2(1-3)$ & $<0.001$ & $3(2-4)$ & $3(2-4)$ & 0.221 \\
\hline $\begin{array}{l}\text { I.V. } \\
\text { thrombolysis }\end{array}$ & $2(3.3 \%)$ & $5(2.6 \%)$ & 0.765 & $2(3.3 \%)$ & $1(1.7 \%)$ & 1 \\
\hline \multicolumn{7}{|l|}{$\begin{array}{l}\text { Laboratory } \\
\text { information }\end{array}$} \\
\hline SBP, mmHg ${ }^{a}$ & $164.16(25.91)$ & $156.35(22.39)$ & 0.023 & $163.42(25.45)$ & $157.07(21.58)$ & 0.143 \\
\hline DBP, mmHg ${ }^{a}$ & $95.67(15.88)$ & $93.06(15.12)$ & 0.246 & $95.23(15.64)$ & $93.97(14.5)$ & 0.646 \\
\hline $\begin{array}{l}\text { Fast glucose, } \\
\mathrm{mmol} / \mathrm{L}^{\mathrm{a}}\end{array}$ & $6.99(3.3)$ & $6.55(2.91)$ & 0.313 & 7.03(3.31) & $7.36(4.03)$ & 0.626 \\
\hline $\mathrm{HbA} 1 \mathrm{c}, \%^{\mathrm{a}}$ & $6.93(2.02)$ & $6.85(2.07)$ & 0.811 & $6.95(2.03)$ & $7.16(2.32)$ & 0.602 \\
\hline
\end{tabular}

Note: END, early neurological deterioration; ${ }^{a}$ Mean (SD), $t$-test; ${ }^{b} n(\%)$, chi-squared test; ${ }^{c} \mathrm{M}(\mathrm{Qu}-\mathrm{QL}), \mathrm{Mann}-$ Whitney Utest; ${ }^{d} n(\%)$, Fisher's exact test; SBP, systolic blood pressure; DBP, diastolic blood pressure; MTLA, medial temporal lobe atrophy; PVH, periventricular hyperintensities; DWMH, deep white matter hyperintensities. 


\begin{tabular}{|c|c|c|c|c|c|c|}
\hline & & Prematched & & & Postmatched & \\
\hline $\begin{array}{l}\text { Total } \\
\text { cholesterol, } \\
\mathrm{mmol} / \mathrm{L}^{\mathrm{a}}\end{array}$ & $5.35(0.99)$ & $5.17(1.21)$ & 0.269 & $5.34(0.99)$ & $1.13(0.27)$ & 0.39 \\
\hline $\begin{array}{l}\text { Triglycerides, } \\
\mathrm{mmol} / \mathrm{L}^{\mathrm{a}}\end{array}$ & $2(1.82)$ & $1.79(1.27)$ & 0.305 & $2(1.83)$ & $1.93(1.4)$ & 0.798 \\
\hline $\begin{array}{l}\mathrm{HDL} \text { cholesterol, } \\
\mathrm{mmol} / \mathrm{L}^{\mathrm{a}}\end{array}$ & $1.1(0.19)$ & $1.22(1.52)$ & 0.524 & $1.1(0.19)$ & $1.13(0.27)$ & 0.448 \\
\hline $\begin{array}{l}\text { LDL cholesterol, } \\
\mathrm{mmol} / \mathrm{L}^{\mathrm{a}}\end{array}$ & $3.55(0.77)$ & $3.44(0.86)$ & 0.366 & $3.54(.078)$ & $3.46(0.91)$ & 0.57 \\
\hline $\begin{array}{l}\text { Homocysteine, } \\
\mathrm{ug} / \mathrm{ml}^{\mathrm{a}}\end{array}$ & $15.43(5.06)$ & 17.05(14.41) & 0.391 & $15.48(5.09)$ & $16.54(5.55)$ & 0.277 \\
\hline $\operatorname{WBC}\left(\times 10^{9} / \mathrm{L}\right)^{\mathrm{a}}$ & 7.91(1.81) & $8.22(3.91)$ & 0.541 & $7.88(1.81)$ & $8.55(4.4)$ & 0.279 \\
\hline $\begin{array}{l}\text { Hemoglobin } \\
(\mathrm{g} / \mathrm{L})^{\mathrm{a}}\end{array}$ & 143(17.49) & 139.44(17.13) & 0.159 & $143.13(17.61)$ & 138.78(16.37) & 0.164 \\
\hline $\begin{array}{l}\text { Fibrinogen } \\
(\mathrm{g} / \mathrm{L})^{\mathrm{a}}\end{array}$ & $3.44(0.73)$ & $3.44(0.87)$ & 0.969 & $3.42(0.73)$ & $3.55(0.88)$ & 0.371 \\
\hline $\begin{array}{l}\text { Prothrombin } \\
\text { time }(\text { INR) })^{a}\end{array}$ & $0.99(0.97)$ & $1.05(0.7)$ & 0.551 & $1(0.98)$ & $1.18(1.26)$ & 0.266 \\
\hline $\begin{array}{l}\text { Creatinine } \\
\text { (umol/L) }^{a}\end{array}$ & 71.46(20.77) & 75.07(25.5) & 0.316 & 71.8(20.76) & 77.15(30.64) & 0.266 \\
\hline \multicolumn{7}{|l|}{$\begin{array}{l}\text { Neuroimaging } \\
\text { information }\end{array}$} \\
\hline \multicolumn{7}{|l|}{$\begin{array}{l}\text { Location of } \\
\text { infarcts }\end{array}$} \\
\hline Cortical region ${ }^{b}$ & $18(29.5 \%)$ & $80(41 \%)$ & 0.106 & $18(30 \%)$ & $35(58.3 \%)$ & 0.002 \\
\hline $\begin{array}{l}\text { Subcortical } \\
\text { region }{ }^{b}\end{array}$ & $52(85.2 \%)$ & 144(73.8\%) & 0.067 & $51(85 \%)$ & $51(85 \%)$ & 1 \\
\hline $\begin{array}{l}\text { Infratentorial } \\
\text { region }\end{array}$ & $6((9.8 \%)$ & $33(16.9 \%)$ & 0.179 & $6(10 \%)$ & $5(8.3 \%)$ & 0.752 \\
\hline Infarct volume ${ }^{c}$ & $\begin{array}{l}2.28(1.14- \\
2.25)\end{array}$ & $\begin{array}{l}0.91(0.42- \\
2.94)\end{array}$ & $<0.001$ & $\begin{array}{l}2.31(1.13- \\
5.29)\end{array}$ & $\begin{array}{l}2.44(0.92- \\
7.34)\end{array}$ & 0.929 \\
\hline MTLA $^{c}$ & $0(0-1)$ & $0(0-1)$ & 0.272 & $0(0-1)$ & $0(0-2.75)$ & 0.146 \\
\hline $\mathrm{PVH}^{\mathrm{c}}$ & $1(0-2)$ & $1(0-2)$ & 0.509 & $1(0-2)$ & $1(0-2)$ & 0.333 \\
\hline $\mathrm{DWMH}^{\mathrm{C}}$ & $1(0-1)$ & $1(0-1)$ & 0.616 & $1(0-1)$ & $1(0-2)$ & 0.929 \\
\hline
\end{tabular}




\begin{tabular}{|c|c|c|c|c|c|c|}
\hline \multirow[b]{2}{*}{ Microbleed $^{\mathrm{C}}$} & \multicolumn{3}{|c|}{ Prematched } & \multicolumn{3}{|c|}{ Postmatched } \\
\hline & $17(27.9 \%)$ & $59(30.3 \%)$ & 0.722 & $17(28.3 \%)$ & $28(46.7 \%)$ & 0.038 \\
\hline Lacunae $^{\mathrm{c}}$ & $26(42.6 \%)$ & $94(48.2 \%)$ & 0.446 & $26(43.3 \%)$ & $33(55 \%)$ & 0.201 \\
\hline \multicolumn{7}{|c|}{$\begin{array}{l}\text { Note: END, early neurological deterioration; }{ }^{\mathrm{a}} \text { Mean (SD), } t \text {-test; }{ }^{\mathrm{b}} n(\%), \text { chi-squared test; }{ }^{\mathrm{c}} \mathrm{M}(\mathrm{Qu}-\mathrm{QL}), \mathrm{Mann}- \\
\text { Whitney Utest; }{ }^{\mathrm{d}} n(\%) \text {, Fisher's exact test; SBP, systolic blood pressure; DBP, diastolic blood pressure; MTLA, } \\
\text { medial temporal lobe atrophy; PVH, periventricular hyperintensities; DWMH, deep white matter hyperintensities. }\end{array}$} \\
\hline
\end{tabular}

Multiple stepwise regression models were used to analyze the effects of END on multiple outcomes (Table 2). END was revealed to be a significant predictor of poor mRS (OR, 3.829; 95\% confidence interval [CI], 1.367-10.723, $p=$ $0.011)$ and $\mathrm{RNLI}(\mathrm{OR}, 2.777 ; 95 \% \mathrm{Cl}, 1.133-6.806, p=0.026)$ scores, after adjusting for confounding factors.

Table 2

Multiple dimensions of poor outcome according to the presence of END, following matching by PSM ${ }^{a}$

\begin{tabular}{|llllll|}
\hline Variables & END & Non-END & $\boldsymbol{\beta}$ & OR $(95 \% \mathrm{Cl})$ & $P$-value \\
\hline ADL & $25(41.7 \%)$ & $16(26.7 \%)$ & 0.848 & $2.335(0.967-5.641)$ & 0.059 \\
\hline mRS & $19(31.7 \%)$ & $8(13.3 \%)$ & 1.343 & $3.829(1.367-10.723)$ & 0.011 \\
\hline RNLI & $26(43.3 \%)$ & $16(26.7 \%)$ & 1.021 & $2.777(1.133-6.806)$ & 0.026 \\
\hline
\end{tabular}

Note: END, early neurological deterioration; PSM, propensity score matching; ADL: activities of daily living; mRS, modified Rankin scale; RNLI, reintegration to normal living index; ${ }^{a}$ adjusted for age, NIHSS on admission, and infarct volume.

\section{Discussion}

In the current study, END affected multiple functional outcomes, including participation restriction and body function impairment. Because END is common in AIS, our results provide insights into the multifaceted nature of functioning after AIS combined with END.

In the present study, the incidence of END was $23.8 \%$, which is consistent with results from previous studies. Current estimates of END incidence after AIS vary widely, and may depend on the definition, type of stroke scales, and time frame used to define this deterioration [5-8].

END may lead to an elevated probability of mortality and poor functional outcomes. As expected, the present results revealed that END was a significant predictor of poor mRS scores $(O R=3.829)$-indicating more severe body function impairments-as reported in previous studies $[13,14,28]$. END also correlated with many clinical factors, such as age, stroke severity, systolic blood pressure, diabetes, and atrial fibrillation [13]. Because mRS scores reflect the overall degree of disability, including both physical function and prognosis [29], it is important to understand and emphasize the role of END in AIS.

END is an important problem in AIS and is correlated with poor functional outcomes. However, previous studies of functional outcomes after stroke combined with END have mainly focused on body function impairments alone, which are often narrowly defined and evaluated only using the mRS [16]. The WHO-ICF categorizes the consequences of disease into three different dimensions: body function impairments, activity limitations, and 
participation restrictions [15]. In the present study, patients with END had a higher risk for poor participation (OR = 2.777) after adjusting for confounding factors using a propensity score analysis. Few previous studies have explored the relationship between END and participation restriction. Stroke survivors often experience participation restrictions in the chronic phase, despite having favorable basic ADLs [17]. Several factors contribute to participation restriction after stroke, including cognitive impairment, emotional deficits, stroke severity, functional dependency, and older age $[30,31]$. We hypothesize that the contribution of END to impaired participation may be influenced by comprehensive risk factors.

Surprisingly, in our study, END was not an independent risk factor for poor ADL after adjusting for confounding factors. The complete ADL requires both dependent basal ADL and satisfactory memory and executive functions. Thus, impairment in ADL is likely influenced by dysfunction in multiple aspects, such as memory and executive function, which may not be related to END.

Our study had some advantages: we assessed the relationship between END and multiple aspects of functional outcomes, and we used propensity score analysis to adjust for confounding factors. Furthermore, we assessed comprehensive MRI variables, which included acute infarct and preexisting brain abnormalities. However, there were also some limitations to our study. First, the sample size was relatively small. Second, we did not assess the NIHSS score at follow-up after stroke, which led to an inadequate evaluation of post-stroke residual neurological deficits. Third, at the follow-up, we did not assess mental function, such as cognitive function, depression, or anxiety, which might be mediators between END and participation restriction.

In conclusion, END is common in AIS, with an incidence of 23.8\%. END might be able to predict poor functional outcomes, including impaired body function and restricted social participation.

\section{Abbreviations}

END, early neurological deterioration

AIS, acute ischemic stroke

mRS, modified Rankin Scale

RNLI, reintegration to normal living index

$A D L$, activities of daily living

NIHSS, National Institutes of Health Stroke Scale

DWI, diffusion-weighted imaging

WMLs, white matter lesions

MTLA, Medial temporal lobe atrophy

WHO-ICF, World Health Organization International Classification of Functioning, Disability, and Health

\section{Declarations}

\section{Availability of data and material}

Page 9/14 
The datasets used and/or analyzed during the current study are available from the corresponding author on reasonable request.

\section{Acknowledgments}

Not applicable.

\section{Funding}

This study was supported by Dongguan people's Hospital Research funding (2017).

\section{Contributions}

Study concept and design: JQ, SW. Acquisition of data: JQ, HZ, WL, YC, YL, Analysis and interpretation of data: HZ, WL, YL, Drafting of the manuscript: JQ. Critical revision of the manuscript for important intellectual content: YC. Statistical analysis: JQ.

\section{Ethical approval and consent to participate}

The study protocol was approved by the Ethics Committee of Dongguan People's Hospital. The consent of all subjects was obtained in accordance with the Declaration of Helsinki.

\section{Consent of publication}

Not applicable.

\section{Competing interests}

The authors declare no conflicts of interest.

\section{References}

1. Zhou M, Wang H, Zeng X, Yin P, Zhu J, Chen W, Li X, Wang L, Wang L, Liu Y, Liu J, Zhang M, Qi J, Yu S, Afshin A, Gakidou E, Glenn S, Krish VS, Miller-Petrie MK, Mountjoy-Venning WC, Mullany EC, Redford SB, Liu H, Naghavi M, Hay SI, Wang L, Murray CJL, Liang X. Mortality, morbidity, and risk factors in China and its provinces, 19902017: a systematic analysis for the Global Burden of Disease Study 2017. Lancet. 2019;394(10204):1145-58. doi:10.1016/S0140-6736(19)30427-1.

2. The GBD 2016 Lifetime Risk of Stroke Collaborators. Global, Regional, and Country-SpecificLifetime Risks of Stroke, 1990 and 2016. New Engl J Med. 2018;25:2429-37. doi:10.1056/NEJMoa1804492.

3. Hou L, Zhang Y, Zheng D, Shi H, Zou C, Zhang H, Lu Z, Du H. Increasing trimethylamine N-oxide levels as a predictor of early neurological deterioration in patients with acute ischemic stroke. Neurol Res. 2020;42(2):1538. doi:10.1080/01616412.2019.1710416.

4. Kwon HM, Lee YS, Bae HJ, Kang DW. Homocysteine as a predictor of early neurological deterioration in acute ischemic stroke. Stroke. 2014;45:871-3. doi:10.1161/STROKEAHA.113.004099.

5. Ferrari J, Knoflach M, Kiechl S, Willeit J, Schnabl S, Seyfang L, Lang W. Austrian Stroke Unit Registry Collaborators. Early clinical worsening in patients with TIA or minor stroke: the Austrian Stroke Unit Registry. Neurology. 2010;74(2):136-41. doi:10.1212/WNL.0b013e3181c9188b. 
6. Kanamaru T, Suda S, Muraga K, Okubo S, Watanabe Y, Tsuruoka S, Kimura K. Albuminuria predicts early neurological deterioration in patients with acute ischemic stroke. J Neurol Sci. 2017;372:417-20. doi:10.1016/j.jns.2016.11.007.

7. Lee SJ, Hong JM, Lee SE, Kang DR, Ovbiagele B, Demchuk AM, Lee JS. Association of fibrinogen level with early neurological deterioration among acute ischemic stroke patients with diabetes. BMC Neurol. 2017;17(1):101. doi:10.1186/s12883-017-0865-7.

8. Li H, Qiu W, Hu B, Kang Z, Wu AM, Dai Y, Lin Y, Lu Z. Ischemic volumes and early neurologic deterioration in acute brainstem infarctions with hemoglobin A1c. Eur Neurol. 2013;70(3-4):225-32. doi:10.1159/000351356.

9. Gong P, Liu Y, Huang T, Chen W, Jiang T, Gong Y, Lu M, Wang M, Zhang Y, Zhang X, Deng Q, Zhou J. The association between high-sensitivity C-reactive protein at admission and progressive motor deficits in patients with penetrating artery infarctions. BMC Neurol. 2019;19(1):346. doi:10.1186/s12883-019-1538-5.

10. Tanaka R, Ueno Y, Miyamoto N, Yamashiro K, Tanaka Y, Shimura H, Hattori N, Urabe T. Impact of diabetes and prediabetes on the short-term prognosis in patients with acute ischemic stroke. J Neurol Sci. 2013;332(12):45-50. doi:10.1016/j.jns.2013.06.010.

11. Dávalos A, Toni D, Iweins F, Lesaffre E, Bastianello S, Castillo J. Neurological deterioration in acute ischemic stroke: potential predictors and associated factors in the European cooperative acute stroke study (ECASS) I. Stroke. 1999;30:2631-6. doi:10.1161/01.str.30.12.2631.

12. Gong P, Zhang X, Gong Y, Liu Y, Wang S, Li Z, Chen W, Zhou F, Zhou J, Jiang T, Zhang Y. A novel nomogram to predict early neurological deterioration in patients with acute ischaemic stroke. Eur J Neurol. 2020 May 20. doi:10.1111/ene.14333.

13. Liu P, Liu S, Feng N, Wang Y, Gao Y, Wu J. Association between neurological deterioration and outcomes in patients with stroke. Ann Transl Med. 2020;8(1):4. doi:10.21037/atm.2019.12.36.

14. Mori M, Naganuma M, Okada Y, Hasegawa Y, Shiokawa Y, Nakagawara J, Furui E, Kimura K, Yamagami H, Kario K, Okuda S, Koga M, Minematsu K, Toyoda K. Early neurological deterioration within 24 hours after intravenous rt-PA therapy for stroke patients: the Stroke Acute Management with Urgent Risk Factor Assessment and Improvement rt-PA Registry. Cerebrovasc Dis. 2012;34(2):140-6. doi:10.1159/000339759.

15. World Health Organization. Towards a Common Language for Functioning, Disability and Health, ICF. Geneva: World Health Organization; 2002.

16. Kapoor A, Lanctôt KL, Bayley M, Kiss A, Herrmann N, Murray BJ, Swartz RH. "Good Outcome" Isn't Good Enough: Cognitive Impairment, Depressive Symptoms, and Social Restrictions in Physically Recovered Stroke Patients. Stroke. 2017;48(6):1688-90. doi:10.1161/STROKEAHA.117.016728.

17. van der Zee CH, Visser-Meily JM, Lindeman E, Jaap Kappelle L, Post MW. Participation in the chronic phase of stroke. Top Stroke Rehabil. 2013;20(1):52-61. doi:10.1310/tsr2001-52.

18. Powers WJ, Rabinstein AA, Ackerson T, Adeoye OM, Bambakidis NC, Becker K, Biller J, Brown M, Demaerschalk BM, Hoh B, Jauch EC, Kidwell CS, Leslie-Mazwi TM, Ovbiagele B, Scott PA, Sheth KN, Southerland AM, Summers DV, Tirschwell DL, American Heart Association Stroke Council. 2018 Guidelines for the Early Management of Patients With Acute Ischemic Stroke: A Guideline for Healthcare Professionals From the American Heart Association/American Stroke Association. Stroke. 2018;49(3):e46-110. doi:10.1161/STR.0000000000000158.

19. Brott T, Adams HP Jr, Olinger CP, Marler JR, Barsan WG, Biller J, Spilker J, Holleran R, Eberle R, Hertzberg V, et al. Measurements of acute cerebral infarction: a clinical examination scale. Stroke. 1989;20(7):864-70. doi:10.1161/01.str.20.7.864.

Page $11 / 14$ 
20. Adams HP Jr, Bendixen BH, Kappelle LJ, Biller J, Love BB, Gordon DL, Marsh EE 3rd. Classification of subtype of acute ischemic stroke. Definitions for use in a multicenter clinical trial. TOAST. Trial of Org 10172 in Acute Stroke Treatment. Stroke. 1993;24(1):35-41. doi:10.1161/01.str.24.1.35.

21. Siegler JE, Schild SM. Early Neurological seterioration (END) after stroke: the END depends on the definition. Int J Stroke. 2011;6(3):211-2. doi:10.1111/j.1747-4949.2011.00596.x.

22. Lawton MP, Brody EM. Assessment of older people: self-maitaining and instrumental activities of daily living. Gerontologist. 1969;9:179-86.

23. Liu JY, Ma KW. The psychometric properties of the Chinese version-reintegration to normal living index (C-RNLI) for identifying participation restriction among community-dwelling frail older people. BMC Geriatr. 2017;17(1):41. doi:10.1186/s12877-017-0424-5.

24. Fazekas F, Kleinert R, Offenbacher H, Schmidt R, Kleinert G, Payer F, Radner H, Lechner H. Pathologic correlates of incidental MRI white matter signal hyperintensities. Neurology. 1993;43(9):1683-9. doi:10.1212/wnl.43.9.1683.

25. Victoroff J, Mack WJ, Grafton ST, Schreiber SS, Chui HC. A method to improve interrater reliability of visual inspection of brain MRI scans in dementia. Neurology. 1994;44(12):2267-76.

26. Chen YK, Xiao WM, Li W, Ni ZX, Liu YL, Xu L, Qu JF, Ng CH, Xiang YT. Microbleeds in fronto-subcortical circuits are predictive of dementia conversion in patients with vascular cognitive impairment but no dementia. Neural Regen Res. 2018;13(11):1913-8. doi:10.4103/1673-5374.239441.

27. Vermeer SE, Longstreth WT Jr, Koudstaal PJ. Silent brain infarcts: a systematic review. Lancet Neurol. 2007;6(7):611-9.

28. Kim YD, Song D, Kim EH, Lee KJ, Lee HS, Nam CM, Nam HS, Heo JH. Long-term mortality according to the characteristics of early neurological deterioration in ischemic stroke patients. Yonsei Med J. 2014 May;55(3):669-75. doi: 10.3349/ymj.2014.55.3.669.

29. van Swieten JC, Koudstaal PJ, Visser MC, Schouten HJA, van Gijn J. Interobserver agreement for the assessment of handicap in stroke patients. Stroke. 1988;19:604-7.

30. Andrenelli E, Ippoliti E, Coccia M, Millevolte M, Cicconi B, Latini L, Lagalla G, Provinciali L, Ceravolo MG, Capecci M. Features and predictors of activity limitations and participation restriction 2 years after intensive rehabilitation following first-ever stroke. Eur J Phys Rehabil Med. 2015;51(5):575-85.

31. Gustavsson M, Guidetti S, Eriksson G, von Koch L, Ytterberg C. Factors affecting outcome in participation one year after stroke: A secondary analysis of a randomized controlled trial. J Rehabil Med. 2019;51(3):160-6. doi:10.2340/16501977-2523.

\section{Figures}




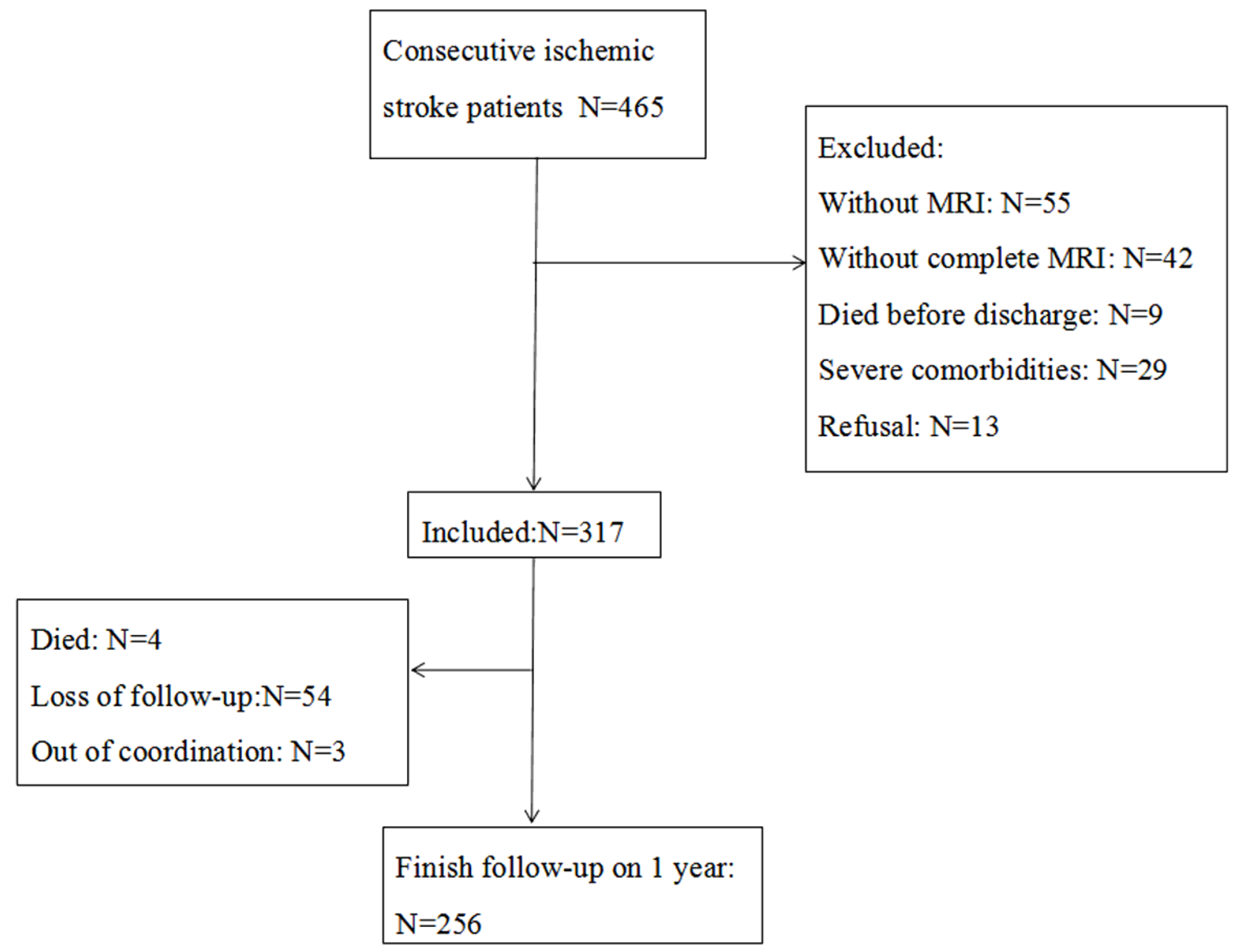

Figure 1

Flow chart of participants. 


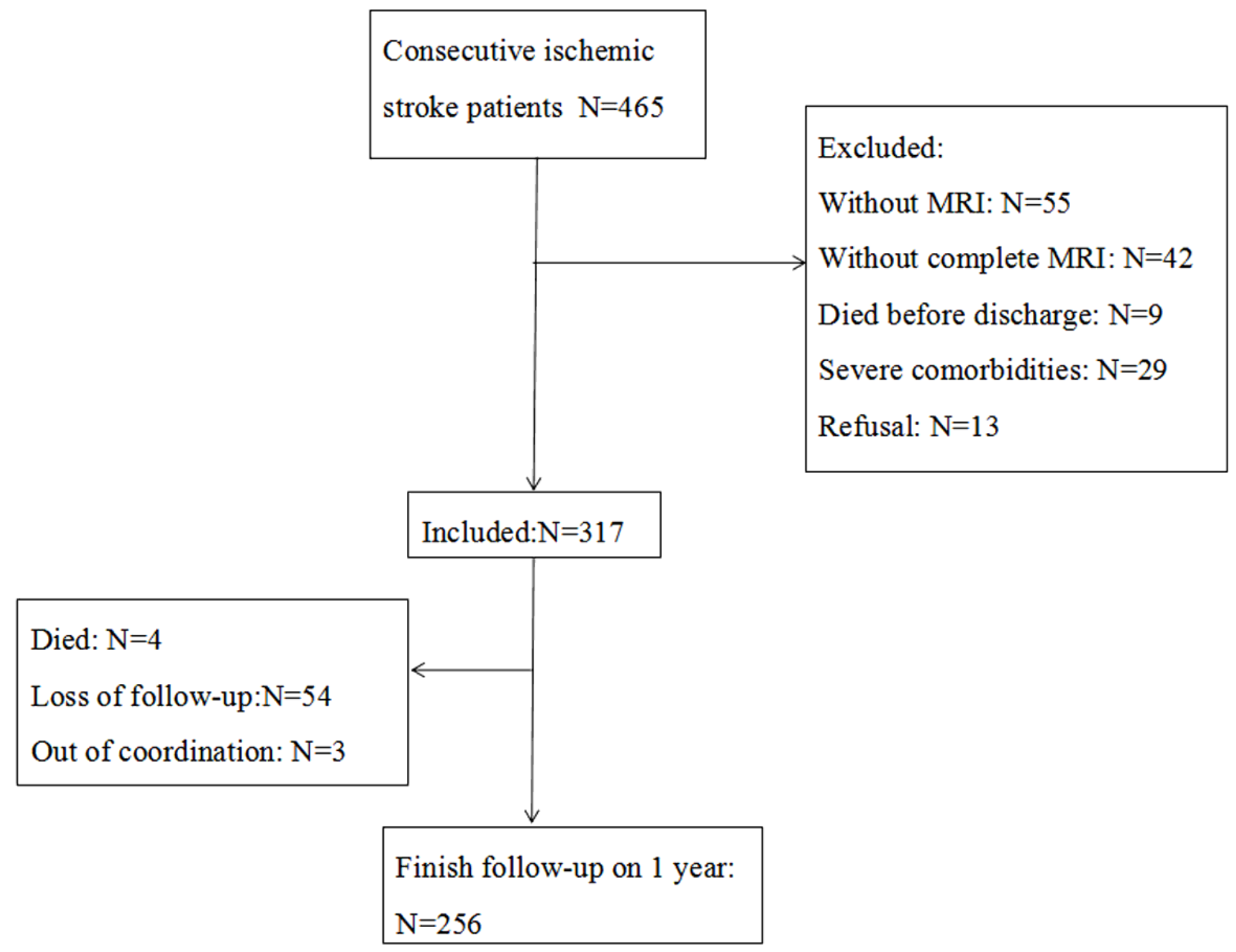

Figure 1

Flow chart of participants. 